\title{
Keeping Brazilians Moving: the importance of urban and transport planning
}

Rev Bras Ativ Fis Saúde p. 271-272

DOI:

http://dx.doi.org/10.12820/rbafs.v.18n3p271

Professor Billie Giles-Corti ${ }^{1}$

In September 2011, a high-level UN meeting brought together leaders from across the globe to discuss the prevention and control of chronic diseases. This meeting acknowledged that the global burden of preventable health conditions such as cardiovascular disease (CVD) and type 2 diabetes was so immense that if uncurbed, it will cripple global health systems and undermine social and economic development.[1]

Globally, the prevalence of chronic diseases is increasing. Currently some 36 million deaths annually are caused by chronic disease, [2] and notably this is in both the developed and developing world. This is particularly disturbing because most chronic diseases are caused by preventable lifestyle-related risk factors: physical inactivity, sedentariness, unhealthy diets and smoking.

While many may say that these behaviours are something that individuals can, and should, fix themselves, in public health circles [3] and increasingly beyond, [1] it is now recognised that global trends in chronic diseases and their major risk factors are thought to be caused by 'system' failure: a system that discourages healthy, and encourages unhealthy life style choices; and as a result creates poor health outcomes and health inequity. [3]

Thus, in 2011 the UN leaders agreed that combatting chronic disease was not something that could be handled by the health sector alone. They concluded that many of the solutions to combating chronic diseases would be found in sectors outside of health: in planning, transport, economics, food production, agriculture, and recreation sectors, to name a few. Decisions made by professionals working in sectors outside of health create the conditions for good (or bad) health.

Importantly, many health and wellbeing outcomes are affected by the way we build and plan cities. For example, city planning affects whether people have access to sidewalks, cycle paths and shops and services, which means they can easily walk or cycle locally; whether jobs are co-located near housing; whether people have access to public transport; whether housing is exposed to noise and other transport-related pollution; whether neighbourhoods are safe, and children can walk safely alone to and from school; whether local food is fresh and healthy, or whether the only food available is fast food and unhealthy; and whether local recreational opportunities are healthy enhancing (e.g., parks or sports centres) or whether they are health-damaging (e.g., focussed on alcohol).

All of these outcomes, directly or indirectly impact the health and wellbeing of citizens, and hence, their chronic disease profiles. Thus, city and transport planning can be used to reduce health inequity.

This idea is not new. In the early $20^{\text {th }}$ century, in the United States, England and Australia, city regulations were used to improve the health of the urban poor profoundly affected by living in crowded housing located in polluted neighbourhoods with poor sanitation. Regulations were introduced to ensure access to sanitation and clean water, to separate land uses thereby reducing exposure to environmental pollution and to specify minimum housing lot size to reduce over-crowding. 
Yet mistakes were made. With the widespread uptake of the motor vehicle post World War II, cities were planned for the car, rather than walking, cycling and public transport use. This has had a significant impact on population physical activity levels as well as the environment, particularly in those less wealthy. Thus, in the $21^{\text {st }}$ century there is now a movement to reduce the predominance of the motor vehicle, and to provide the infrastructure and land use planning that will encourage walking, cycling and public transport use. From a health perspective, the decisions about the way we plan our cities definitely matters.

As the world urbanises, the way we plan cities will become even more important to protect the health and wellbeing of our citizens. Public health professionals and researchers can, and should, take part in the debate about city planning to ensure that we ensure we deliver the best possible cities for our residents: cities that are more healthy and equitable.

However, to do so, we need to be educate ourselves and be aware of the co -benefits associated of good city planning. $[4,5]$ The term 'co-benefits' is used when considering benefits across multiple policy areas. For example, investment in city planning that encourages active transport (e.g., walking, cycling and public transport) has the potential to produce substantial co-benefits across multiple sectors including reduced greenhouse gas emission, improvements in air quality, enhanced health from both increased physical activity and reduced exposure to air pollution as well as impacts on productivity by reducing traffic congestion and the efficiency of the city. $[6,7]$

Importantly, to create health, wellbeing and prosperity for citizens will require leadership and a long term commitment to a city plan. Not the plan of one government: but a long term plan of the city that goes beyond a political cycle. This will require negotiation between political parties to agree on the key ingredients of a good city plan (e.g., land use and transport planning that ensures there is access to public transport and a focus on walking and cycling). At the heart of these agreements should be the aim of a long term commitment to optimizing health and wellbeing outcomes, and thus a creating healthy, equitable, prosperous and sustainable future for Brazilian citizens and cities, and ultimately for Brazil itself.

\section{RERFERÊNCES}

1. United Nations. Sixty seventh session Political Declaration of the High Level meeting of the General Assembly on the Prevention and control of non-communicable diseases. 2011; Available from:

2. http://www.un.org/ga/search/view_doc.asp?symbol=A/66/L.1.

3. Lozano, R., et al., Global and regional mortality from 235 causes of death for 20 age groups in 1990 and 2010: a systematic analysis for the Global Burden of Disease Study 2010. Lancet, 2012. 380: p. 2095-2128.

4. Marmot, M., Fair society, healthy lives. Strategic review of health inequalities in England post2010, 2011, UCL Institute for Health Equity: London.

5. Giles-Corti, B., et al., The co-benefits for health of investing in active transportation. New South Wales Public Health Bulletin, 2010. 21: p. 122-7.

6. Rissel, C.E., Active travel: a climate change mitigation strategy with co-benefits for health. New South Wales public health bulletin, 2009. 20(1-2): p. 10-13.

7. Mohan, D. and D. Tiwari, Sustainable transport systems, linkages between environmental issues. Public transport, non-motorised transport and safety. Economic and Political Weekly, 1999. XXXIV(25): p. 1580-1596.

8. Woodcock, J., et al., Public health benefits of strategies to reduce greenhouse-gas emissions: urban land transport. Lancet, 2009. 374: p. 1930-43. 